\title{
El sujeto artificial en el cuento «Artemio y Multical», de José B. Adolph
}

\author{
The artificial subject in the story «Artemio $y$ \\ Multical», by José B. Adolph
}

\section{O sujeito artificial na história «Artemio y Multical», de José B. Adolph}

\author{
Carlos Enrique Saldívar ${ }^{1}$ \\ Universidad Nacional Federico Villarreal (Perú) \\ carlosenriquesaldivar@gmail.com
}

Fecha de recepción: 18 de julio de 2019

Fecha de recepción evaluador: 20 de agosto de 2019

Fecha de recepción corrección: 15 de octubre de 2019

\footnotetext{
${ }^{1}$ Carlos Enrique Saldívar. Director de la revista Argonautas y del fanzine El Horla; miembro del comité editorial del fanzine Agujero Negro. Director de la revista Minúsculo al Cubo. Finalista de los Premios Andrómeda de Ficción Especulativa 2011, en la categoría: relato. Finalista del I Concurso de Microficciones, organizado por el grupo Abducidores de Textos. Finalista del Primer concurso de cuento de terror de la Sociedad Histórica Peruana Lovecraft. Finalista del XIV Certamen Internacional de Microcuento Fantástico miNatura 2016. Finalista del Concurso Guka 2017. Publicó los libros de cuentos Historias de ciencia ficción (2008, 2018), Horizontes de fantasía (2010); y el relato El otro engendro (2012). Compiló las selecciones: Nido de cuervos: cuentos peruanos de terror y suspenso (2011), Ciencia Ficción Peruana 2 (2016), Tenebra: muestra de cuentos peruanos de terror $(2017,2018)$ y Muestra de literatura peruana (2018). ORCID: https://orcid.org/0000-0003-0527-9912
} 


\title{
Resumen
}

En el presente ensayo se intentará analizar algunos detalles no mostrados de forma explícita en el cuento «Artemio y Multical», incluido en el libro Mañana fuimos felices (1975), del escritor peruano José B. Adolph, con el fin de explicar algunos aspectos que no son explícitos en la ficción. Se partirá de algunas consideraciones que se basan en el planteamiento de la narración, luego se tratará la crítica social implícita en el mismo, para pasar hacia la ciencia ficción, género en el que se inscribe la obra. Para ello, se mencionará ciertos referentes relacionados con lo tecnológico y lo científico, para fundamentar el análisis del sujeto artificial, partiendo de la unificación del objeto y lo humano; la finalidad es descubrir temas recurrentes, como el amor. La pretención es ver la mirada evolutiva del sujeto artificial, desde el objeto y lo humano, hasta el estadio del superhombre, además de las cualidades que implican tal condición. Con ello se tratará de dilucidar algunos aspectos relacionados con el relato de ciencia ficción peruano que se escribía en el siglo pasado.

Palabras clave: José B. Adolph; Ciencia ficción; Tecnologías; Sujeto artificial; Análisis crítico.

\begin{abstract}
This essay will attempt to analyze some details not explicitly shown in the story "Artemio y Multical", included in the book Mañana fuimos felices (1975), by the Peruvian writer José B. Adolph, in order to explain some aspects that They are not explicit in fiction. It will start from some considerations that are based on the narrative approach, then the implicit social criticism will be treated, to move towards science fiction, a genre in which the work is inscribed. For this, certain references related to the technological and the scientific will be mentioned, to support the analysis of the artificial subject, based on the unification of the object and the human. The purpose is to discover recurring themes, such as love. The pretention is to see the evolutionary look of the artificial subject, from the object and the human, to the stage of the superman, in addition to the qualities that imply such a condition. This will try to elucidate some aspects related to the Peruvian science fiction story that was written in the last century.
\end{abstract}

Keywords: José B. Adolph; Science fiction; Technologies; Artificial subject; Critical analysis.

\section{Resumo}

Este ensaio tentará analisar alguns detalhes não explicitamente mostrados na história “Artemio y Multical”, incluída no livro Mañana fuimos felices (1975), do escritor peruano José B. Adolph, a fim de explicar alguns aspectos que eles não são. explícito na fíç̧ão. Partirá de algumas considerações baseadas na abordagem narrativa e, em seguida, serão tratadas as críticas sociais implícitas, para avançar em direção à ficção científica, um gênero no qual a obra está inscrita. Para isso, serão mencionadas algumas referências relacionadas ao tecnológico e ao científico, para subsidiar a análise do sujeito artificial, 
com base na unificação do objeto e do humano. O objetivo é descobrir temas recorrentes, como o amor. A pretensão é ver o olhar evolutivo do sujeito artificial, do objeto e do humano, até o estágio do super-homem, além das qualidades que implicam tal condição. Isso tentará elucidar alguns aspectos relacionados à história de ficção científica peruana que foi escrita no século passado.

Palavras-chave: José B. Adolph; Ficção cientifica; Tecnologias; Sujeito artificial; Análise Crítica.

\section{Introducción}

José B. Adolph (Stuttgart, Alemania, 1933-Lima, Perú, 2008) fue un escritor peruano que trabajó con solvencia el cuento y la novela, entre otros géneros literarios. Dentro de la primera vertiente produjo muchos buenos relatos de toda clase: realistas, fantásticos, de terror, de misterio, policiales, extraños, metafísicos, alegóricos, oníricos, etc.; pero existe una corriente artística en la que produjo textos con una intensidad singular: la ciencia ficción; tanto en la novela como en el relato corto. Por ello, hoy en día, puede ser considerado quizá el máximo representante de la ciencia fícción peruana.

El cuento que voy a analizar en esta oportunidad es uno de sus trabajos más logrados y representativos, se trata de «Artemio y Multical», incluido en el libro Mañana fuimos felices (INC, Lima, 1975). Mi trabajo se enfocará en el sujeto artificial, el cual es uno de los dos protagonistas de la historia. El sujeto artificial aquí es la computadora Multical.

\section{Algunas consideraciones}

Ambientado en 1973, el cuento toma a Lima como escenario inicial. El primer protagonista es Artemio Ayar, véase el apellido que remite de inmediato a la leyenda de los hermanos Ayar, en ella se narra el supuesto proceso de fundación del Cusco, esto resulta muy interesante pues se menciona que el protagonista es una personalidad relevante en el mundo epistémico del cuento. En relación con ello, en el texto se hace referencia a muchas proezas del cálculo mental matemático; es oportuno decir que hasta este punto la ficción se asemeja a la realidad, pues el cálculo mental es posible y al presente se han realizado torneos mundiales de esta disciplina. A la par de esta introducción, se presenta al segundo protagonista: una computadora (se presume que es de tres metros cúbicos y de origen norteamericano, que ha sido traída al Perú por un técnico para introducirla al mercado nacional). Lo que queda claro es que fue traída por los ejecutivos de una célebre firma de computadoras. El nombre del armatoste es Multical 560 Ultra. La inteligencia de Artemio es sometida a pruebas por la Universidad del Cusco debido a sus notables aciertos en el ámbito del cálculo mental y su gran rapidez de aprendizaje con respecto a los conceptos matemáticos. Aquí hay un guiño a la biografía de Albert Einstein, e incluso Adolph lo menciona en su prólogo al libro: "Lo que más 
impresionó a las multitudes de Einstein no fue la teoría de la relatividad, sino que fuera malo en Aritmética y comiera caramelos" (1975, p. 11).

Artemio es un ser humano con una gran capacidad y eso genera la admiración de sus coetáneos. Pero antes de que su destreza fuese descubierta se le consideraba casi un retrasado mental. Artemio luego se convierte en una suerte de celebridad local. El encuentro entre el adolescente y la computadora tiene lugar en Lima, frente a un público; les son presentados a hombre y máquina una serie de problemas aritméticos y ambas responden «casi guales», con una ligerísima ventaja en décimos de segundo a favor del joven cusqueño. Aquí se mantiene la superioridad del hombre sobre la máquina, donde se sugiere que el ser humano ha de dominar a la tecnología y no debe ser a la inversa. Se siguen planteando más problemas y Artemio supera al artefacto siempre por un estrecho margen. Entonces comienza el verdadero conflicto, el cual trataré en el último punto de este análisis.

\section{La crítica social}

Existe una crítica a la modernidad, una constante en la obra de Adolph, nótese un fragmento en el texto que indica el fallo de la tecnología y la superioridad de cálculo del individuo ante esta:

- Mira, taita -insistió Artemio, e hizo su cálculo con lápiz y papel ante el empleado: 83,540.55. Tras quince minutos de sucesivos cálculos y contrapruebas, el bancario se rindió ante la evidencia, la máquina se había equivocado. Un profundo misterio, se dijo, y pagó los cien soles más. (Adolph, 1975, p. 41)

Este punto es muy importante, porque vulnera el universo tecnológico planteado en el texto, mostrando que existe una imperfección en el objeto artificial y se genera una mayor confianza en la capacidad del sujeto humano. Además, es necesario ver la banalización del hombre: Artemio se convierte en poco más que un espectáculo debido a su talento es mostrado ante un público y lo someten a todo tipo de pruebas, se le promete incluso, al terminar la exhibición junto a Multical, que "debía volver a su tierra donde le esperaba una generosa beca en un Instituto de Matemática anexo a la Universidad y, luego, el prometido viaje a Norteamérica" (Adolph, 1975, p. 46).

El crítico literario y cultural italiano Franco Ferrini nos dice en su libro ¿Qué es verdaderamente la ciencia ficción? lo siguiente:

Por una parte, el progreso científico y tecnológico exalta el ideal milagrero de la perfectabilidad de todas las cosas, sin excluir la sociedad humana; por otra parte, con las fuerzas que este mismo progreso consigue desencadenar, se le imprime un estado de inquietud y desfallecimiento general. (1971, p. 52).

Esto no queda patente en el desarrollo del cuento del cual hablamos, pero sí en su extraordinario desenlace. 


\section{La ciencia ficción}

Este aspecto es indudable: los robots, las máquinas pensantes y los hombres artificiales son temas propios de la ciencia ficción. ¿Qué es la ciencia ficción? Una definición posible del género es la propuesta por los escritores Eduardo Gallego y Guillem Sánchez en su artículo «¿Qué es la ciencia-ficción?»:

La ciencia ficción es un género de narraciones imaginarias que no pueden darse en el mundo que conocemos, debido a una transformación del escenario narrativo, basado en una alteración de coordenadas científicas, espaciales, temporales, sociales o descriptivas, pero de tal modo que lo relatado es aceptable como especulación racional. (2003, párr. 59)

Esta definición es una de las más aceptadas a nivel mundial, posee una gran amplitud de miras y quizá por ello es bastante funcional para aquellos que estudian tal vertiente.

La ciencia ficción ha tratado el tema de la inteligencia artificial en diversas obras, una buena presentación del sujeto artificial puede verse en la película Inteligencia artificial (2001), escrita en parte por Ian Watson junto a Steven Spielberg, además dirigida por este. En dicho filme el androide, creación humana, es programado para tener unos sentimientos afectivos especiales, sobre todo hacia su «madre».

Desde siempre, la ciencia ficción ha tratado el tema de seres artificiales, robots que adquieren consciencia y deciden actuar diferente a lo estipulado o incluso rebelarse contra sus creadores (historias derivadas de Frankenstein o el Moderno Prometeo de Mary Shelley [1818], considerado el primer relato de ciencia ficción de la historia de la literatura y texto precursor del sujeto artificial en esta).

Por supuesto, además se ha tratado mucho el tema de la máquina que se humaniza. En «Artemio y Multical» tenemos el tópico de la máquina pensante, el cual es deudor de grandes obras maestras del relato corto.

"Respuesta" [en Angels and Spaceships, 1954], de Fredric Brown, es un ejemplo. Se construye una súper calculadora, capaz de responder cualquier pregunta, entonces su creador le consulta “¿Existe un Dios?”, y la máquina cibernética le responde: "Sí, ahora existe un Dios" (1977, p. 14).

Otro cuento representativo es sobre la computadora «Multivac», "Todos los males del mundo" [1958] de Isaac Asimov (véase el guiño a ese personaje artificial que aparece en varios cuentos del buen doctor, el nombre «Multical» es muy parecido a «Multivac»). En aquel relato Multivac, la supercomputadora que controla la vida de millones de personas, diseña su propio asesinato debido al estrés que padece. Cuando los técnicos le preguntan a Multivac “¿Qué deseas más que ninguna otra cosa?”, esta responde: “Quiero morir" (Asimov, 2017, p. 367).

Aunque, de seguro, el cuento definitivo sobre una máquina que, al responder un cuestionamiento, accede al estado de dios es "La última pregunta" [1956], de Isaac 
Asimov, obra maestra de la cual recomiendo su lectura para que se entiendan las posibilidades de un sujeto artificial que se reconoce a sí mismo como máquina primero, luego se humaniza y finalmente va más allá del mismo hombre.

Las tesis de los escritores de ciencia ficción son encontradas; por un lado, hay quienes confían en la infalibilidad de las máquinas y en una convivencia armoniosa con los sujetos artificiales, en tanto hay otros que no piensan así. En «Artemio y Multical» se unifican ambas posturas, por eso es un cuento de gran relevancia.

\section{El sujeto artificial}

Hablemos ahora del sujeto artificial. Alma Delia Zamorano Rojas nos dice en su ensayo «En busca del sujeto perdido: Inteligencia Artificial» lo siguiente:

Para algunos autores los orígenes del sujeto están en la razón, pues el mundo real es cuestionable y el mundo ideal no es seguro, ya que toda trascendencia ha sido puesta entre paréntesis. Sin embargo, el sujeto está ahí, pero no para tomar conciencia, pues la razón ha quedado vacía, la cadena de razonamientos se ha agotado y la duda ha acabado con todo; está solo consigo mismo. (2009, p. 141)

Si es permisible considerar que un objeto se convierte en sujeto porque ha descubierto la razón, podríamos afirmar que Multical se convierte en un sujeto artificial en el momento en que reacciona de modo «humano» ante Artemio. El proceso de adquisición de la razón de una máquina dentro de la ciencia ficción no ha sido explicado satisfactoriamente por la mayoría de autores y el salto de un estado (objeto) a otro (sujeto) se da generalmente porque sí, sin que esto genere mayor problema en el desarrollo de las historias, pues, generalmente, al ser la fantasía científica una vertiente que se dedica a extrapolar ideas, e ideas sobre ideas, puede muy bien prescindir de una explicación científica para analizar un fenómeno, a fin de poder desarrollar después, con rigor especulativo, la problemática que implica la existencia de un sujeto artificial consciente de sí mismo, del mundo que lo rodea, y de sus propias posibilidades.

Veamos a continuación los tres estadios de este sujeto artificial.

\section{a) El objeto}

La máquina, en este caso la computadora que posee una habilidad es capaz de solucionar intrincados problemas matemáticos, aunque la virtud es la misma que posee Artemio. Multical no deja de ser un artefacto y no posee el mismo valor que el ser humano. Es decir, las capacidades del objeto y el sujeto son las mismas para una actividad específica, pero la valoración de los otros sujetos hacia ambos es distinta. Es aquí donde empalmo con lo tratado en el punto uno. Prestar atención a esta parte: "Luego el técnico, sin dejar de sonreír, acarició el brillante lomo gris de Multical. Artemio observó con un raro fulgor ese gesto, y calló” (Adolph, 1975, p. 43).

¿Celos? Es importante notar cómo todo cambia a partir de este punto en la narración. Artemio, a diferencia del resto de espectadores, observa al aparato con otros ojos y le atribuye alguna cualidad humana femenina. Veamos este otro fragmento: 
Mientras se preparaba una nueva serie de experimentos, a riesgo ya de cansar a la audiencia, Artemio -que no había dejado de mirar de reojo a Multical-, haciendo evidentemente un gran esfuerzo, se incorporó y con pasos lentos y medidos se acercó a la máquina. La rodeó, mirándola por todos lados, mientras el técnico, cruzado de brazos, observaba en silencio. Artemio se inclinó para ver algún detalle, pasó la mano sobre la cubierta, introdujo el dedo en una abertura, apretó este y aquel botón. Multical zumbaba como una gata. (Adolph, 1975, p. 43) del hombre.

La máquina primero ha pasado a un estado animal, ha reaccionado ante el cortejo

Poco a poco el objeto pasa al segundo estadio:

\section{b) El humano}

Durante este proceso el artefacto adquiere conciencia.

Uno de los mejores cuentos que refleja este estadio es "El hombre bicentenario" (1986), de Isaac Asimov, donde un robot adquiere la condición de humano.

Volviendo al texto de análisis, véanse los rasgos humanos que se le atribuyen a la computadora: "Artemio jugó con su nueva amiguita y aprendió a hacerla calcular", "Multical tuvo algo así como un acceso de tos", "Multical (...) comenzó a zumbar suavemente" (Adolph, 1975, p. 44).

Artemio le propone un problema de astronomía y se produce una conexión psíquica entre el humano y la computadora, el técnico no le formula la pregunta, lo hace el chiquillo con solo mirarla y esperar:

El profesor, repuesto de la sorpresa, preguntó:

—Artemio, ¿tú sabes cómo respondió la máquina?

- Sí, yo le dije que contestara a la pregunta tuya.

—CCómo le dijiste? escapen.

—Así como le digo al perro que me acompañe o a los carneros que no se me

—iPensando nomás?

—Sí, pues, doctor. (Adolph, 1975, pp. 44-45).

Aquí se revela un don de Artemio, es llamado «telepatía» (fenómeno parapsicológico consistente en la transmisión de pensamientos o sensaciones entre dos sujetos, generalmente distantes entre sí, sin la intervención de los sentidos). Siguen las atribuciones de carácter no mecánico a Multical: "ronroneaba, muy satisfecha de sí misma y de su amigo cusqueño" (Adolph, 1975, p. 45). 
Se le atribuye incluso un carácter femenino. Artemio sigue siendo un espectáculo, se le propone ir a Estados Unidos pues la combinación de los poderes de un telépata y un calculador mental es «extremadamente rara» (no obstante, se indica que los telépatas sí son conocidos, al menos en Estados Unidos). Es aquí donde surge un incidente, Artemio no desea separarse de Multical y se le permite pasar la noche con ella, enchufada, para realizar nuevos cálculos y «probándola a su entera satisfacción».

Se le siguen dando rasgos femeninos a la máquina: "un sonriente muchacho abrazando primero, y besando entusiastamente después, a Multical” (Adolph, 1975, p. 46).

A Artemio se le atribuyen cualidades propias del hombre cortejador:

Artemio Ayar siguió, con mirada preocupada y vigilante, los ajetreos cuidadosos que acompañaron el transporte de Multical”, “(...) observó al técnico que enchufaba la máquina y la dejaba en estado de funcionamiento, con ese lejano y cariñoso zumbido que evidentemente transportaba a Artemio Ayar. (Adolph, 1975, pp. 46-47)

El narrador realiza guiños al aspecto romántico: “(...) los ejecutivos y el técnico se retiraron tras los periodistas, no sin antes desear una buena noche a un feliz Artemio." (Adolph, 1975, p. 47).

Lo que ocurre aquella noche no se menciona en el relato, aunque todos los indicios previos apuntan a un encuentro sexual entre Artemio y Multical, pero es un encuentro sexual ¿de qué tipo?

Aquí entramos al tercer estadio de este sujeto artificial:

\section{c) EI superhombre:}

Artemio es encontrado muerto a la mañana siguiente, había fallecido de un paro cardíaco por electrocución. Citemos algunas secciones del cuento:

La máquina seguía enchufada, pero no funcionaba”, “(...) la máquina no mostraba ningún indicio de sobrecarga", "Multical, por su parte, no funcionó más", "Un trágico, pero simple caso de eletrocutación (...). Hubiera sido absurdo suponer cualquier otra cosa. (Adolph, 1975, p. 47)

Una digresión: véase que el absurdo ha sido un aspecto muy importante en el texto.

Por otro lado, en su prólogo, José B. Adolph nos habla de la importancia del amor. Es necesario recalcar que en este cuento se hace presente un rasgo muy importante de la obra de Adolph, la unificación del Eros y del Thánatos, el amor conlleva a la muerte, la muerte es resultado del amor, o amor y muerte van irremisiblemente ligados. También es de suma importancia mencionar el tema que desencadena la aparición del amor que luego desemboca en la muerte: el superhombre. Esta figura es bastante frecuente en la ciencia ficción. Claramente, Artemio posee la habilidad de comunicarse con otros seres a través 
del pensamiento, al utilizar dicha habilidad con Multical hace que esta comience a desarrollar una conciencia, lo cual origina un vínculo afectivo hacia este ser humano.

Los relatos de androides que se enamoran de hombres y mujeres han estado presentes muchas veces en la ciencia ficción, en "Helen O Loy" [1938], por ejemplo, del estadounidense Lester Del Rey, o en "El cinturón del robot" [1955], del francés Yves Dermeze.

Pero volvamos al superhombre. En su libro ¿Qué es verdaderamente la ciencia ficción?, Franco Ferrini nos habla de este tópico:

La ciencia ficción, a través de la introducción del superhombre, intenta desplazar la medida de la definición del hombre. Ahora se hace posible un nuevo tipo de humanidad, distinta de esa otra lisa y cotidiana, surgida como reacción a la mediocridad del mundo que la rodea”. (1971, p. 127).

Artemio tenía poderes psíquicos y esto, como vemos, es un tema de la ciencia ficción. Era un superhombre. Se pueden especular muchas cosas sobre lo que sucedió aquella noche entre Multical y el joven, ¿podría la máquina haber asesinado al humano por envidia ante su superioridad para luego imitar su don y desplazarlo? No. Imposible, durante todo el texto se han brindado indicios de una respuesta afable de la computadora hacia el muchacho. Se amaron, hicieron el amor, mas no de un modo convencional. Aquella noche, especulo, Multical, que ya había alcanzado la humanidad, logró acceder al estadio de superhombre también y la fusión amorosa de ambas mentes causó la muerte de ambos sujetos. Nunca se sabrá lo que vieron, lo que sintieron, lo que descubrieron, lo que entendieron durante la consumación de dicho acto, tal vez ambos rozaron lo divino, todo gracias a la adquisición de aquella conexión especial que solo pueden tener dos fuerzas que se unen, dejan de ser solo fuertes y se vuelven poderosas.

\section{Bibliografía}

Adolph, J.B. (1975). Mañana fuimos felices. Lima: INC.

Asimov, I. (2017). La última pregunta. En Cuentos completos: Vol. I (4a., pp. 385-399). Bogotá: B Zeta Bolsillo.

Asimov, I. (2017). Todos los males del mundo. En Cuentos completos: Vol. I (4a., pp. 350-367). Bogotá: B Zeta Bolsillo.

Asimov, I. (1986). El hombre del bicentenario. Buenos Aires. Hyspamerica.

Brown, F. (1977). La respuesta. En D. Knight (Ed.), Sonrisas de metal (Vol. 15, pp. 1314). Barcelona: Luis de Caralt.

Brown, F. (1954). Angels and Spaceships. New York: V. Gollancz \& E.P. Dutton.

Ferrini, F. (1971). ¿Qué es verdaderamente la ciencia ficción? Madrid: Doncel. 
Sánchez, G., \& Gallego, E. (2003, diciembre 1). ¿Qué es la ciencia ficción? [Página web]. Recuperado de Sitio de ciencia-ficción website: https:/www.cienciaficcion.com/opinion/op00842.htm

Shelley, M.W. (2001). Frankenstein. Madrid: Suma de Letras.

Spielberg, S. (2001). Artificial Intelligence: AI [Ciencia ficción, Drama, Filme]. Recuperado de http://www.imdb.com/title/tt0212720/

VV.AA. (1969). Los mejores relatos de anticipación. Barcelona: Bruguera.

VV.AA. (1971). Antología de novelas de anticipación XIII. Barcelona: Acervo.

VV.AA. (1978). Los hombres paradójicos. Barcelona: Luis de Caralt Editor.

VV.AA. (1979). Almas de metal. Buenos Aires: Lidiun.

VV.AA. (2003). Sistema Binario. Barcelona: Asociación Cultural Mundo Imaginario.

Zamorano Rojas, A. D. (2009). En busca del sujeto perdido: Inteligencia artificial. Argumentos, 22(60), 139-162. https://www.redalyc.org/pdf/595/59512089008.pdf 